\title{
LEVELS OF PRO-ENVIRONMENTAL MATURITY IN MICRO AND SMALL ENTERPRISES
}

doi: $\quad 10.2478 /$ czoto-2019-0033

Date of submission of the article to the Editor: $02 / 12 / 2018$

Date of acceptance of the article by the Editor: 18/01/2019

Robert Kucęba - orcid id: 0000-0002-3904-0523

${ }^{1}$ Czestochowa University of Technology, Poland, robert.kuceba@wz.pcz.pl

Abstract: The underlying objective of the paper is to indicate pro-environmental awareness level in micro and small enterprises and its influence on this sector's activity in the context of environmental management. The author has introduced a taxonomy of pro-environmental awareness and also pro-environmental security, proenvironmental culture and pro-environmental ethics. Heterogeneous proenvironmental attitudes of units/entities (including business entities) have been aggregated in the paper, in the context of their transformation from a passive towards active attitude. The elaborated levels of pro-environmental awareness growth have been summarised in a chronological grasp, which constituted the subject of the research with reference to the subject matter of the paper defined in its title. The author has also justified the selection of the research subject - micro and small enterprises, which are a source of surface contamination (local one), but not always perceived as beneficiaries of the natural environment.

With reference to the adopted subject of the research the author has made an attempt to evaluate the pro-environmental awareness of the purposefully selected population of micro and small enterprises. Maturity level of their pro-environmental awareness has also been evaluated according to the adopted scale described and explained in the theoretical part of the paper, which is a narrow part of the conducted research and an attempt to answer the question: What is the maturity level of pro-environmental awareness in micro and small enterprises and is it reflected in their green activity in the conducted business activity?

Keywords: micro and small enterprises, pro-environmental awareness, proenvironmental security, environmental management,

\section{INTRODUCTION}

Presently, while discussing social security one cannot overlook an essential compound which is pro-environmental security. This security has been frequently defined in the literature on the subject (Liu and Chang, 2015) as the condition of the ecosystem in which the risk of disturbing its compound has been eliminated (zero risk) or reduced. It should be stressed that this condition can be maintained, guaranteed only if these actions are holistic and carried out in accordance with the bottom-up approach, beginning with changes to pro-environmental behaviours of individuals, 
elementary business entities - to system changes in the whole of the society. Only such actions can guarantee common pro-environmental security. However, it can be observed that the relationships between caring for the natural environment in the conditions of increased man's activity (frequently associated with contamination or even degradation of the environment), still often occur in dissociation. Despite the fact that it was already in the past century that this dissociation was perceived, in particular in the area of a negative influence of the diffusion of economies industrialisation on the natural environment, steps taken at that time to increase the pro-environmental security were limited to centralised actions (top-down ones) in the scope of resource rationalisation and natural environment protection. Frequently they were purely of legislative or political nature, referring to geophysical macro-regions as well as economic ones. The approach to the natural environment is also convergent with the sustainable development trend (Bos-Brouwers, 2010) as well as social responsibility. Currently, in accordance with the commonly accepted standard of sustainable development there exists an aspiration to integrate political, economic, environmental and social actions, which is thought to guarantee satisfying basic needs of particular communities or citizens, both in case of contemporary as well as future generations. However, actions associated with this standard need to be economically justified, symbiotic with the natural environment and fully accepted by the society. Thus, the importance of pro-environmental culture needs to be stressed here, which in the context of the subject matter defined in the paper's title can be reasonably defined as a compound of a general human culture - the set of values, standards, ideals, behaviour patterns and ethical attitudes towards the natural environment as well as an ability to coexist in this environment and rationally utilise available resources. While discussing pro-environmental culture it should be stressed that its growth is proportionally related to the growth in pro-environmental awareness. Therefore, in order to achieve a positive convergence between care for the natural environment and contemporary economic activity it is vital to increase the proenvironmental awareness, which influences a change in pro-environmental attitudes from so called indifferent (defensive) ones towards active (offensive) ones. Thus, active attitudes of heterogeneous units/entities towards the natural environment can influence conscious undertaking of green activity and therefore the willingness to incur larger external costs, which in turn has a stimulating impact on pro-environmental security and simultaneously social security. While discussing pro-environmental activeness these actions need to be continuous and permanent.

\section{EMPOWERMENT OF ENVIRONMENTAL IMPACT}

In order to achieve the desired pro-environmental state that ensures a peaceful and healthy existence of all the eco-system's elements, all elementary units/entities need to be activated, particularly the ones that are or can be a potential source/"producer" of environmental, and therefore social, threats. In the group of these entities, referring to the secondary research „(..) personal impact on the environment (...), conducted in 2014 by the Social Research Office INDEKS, on commission of the Our Earth Fund, the strongest impact was assigned to an individual - man (89\% of indications). Other distinguished in this research entities that have a direct impact on the natural environment include: city authorities ( $28.5 \%$ of indications), state authorities (28.5\% of indications), industrial plants (26.9\% of indications), waste disposal companies in cities and municipalities (16.4\% of indications), environmentalists (8.8\% of indications) 
and other entities $(0.8 \%$ of indications). In order to make these results more legible it needs to be stressed that in this secondary research each of the respondents could indicate three entities (Social Research Office INDEKS, 2014).

In the context of the abovementioned research, as well as the conducted literature query, entities that have both negative and corrective impact on the natural environment, apart from an autonomous individual, are often limited to state, regional, economic, industrial institutions (in this case up to large or medium-sized enterprises). Micro and small enterprises, which are usually sources of surface contamination (local one), are frequently omitted or included into the other summarised above groups of entities. This is perceived as a research gap. This research gap can be justified by the size of this group of enterprises, their number or added value in the economy. For example, according to the data by the Main Statistical Office (GUS) in 2016 there were 2013364 non-financial companies registered in Poland, in this $96.2 \%$ of microenterprises and $2.8 \%$ of small enterprises. Moreover, these entities generate over $60 \%$ of the GDP and employ $70 \%$ of the total number of employed persons. The presented above examples of quantitative ratios referring to the size of micro and small enterprises justify their value and holistic impact on the state economy and therefore a strong influence on the environment (Hoogendoorn et al., 2015). While justifying the domination of micro and small enterprises and their influence on the proenvironmental security one should also indicate their ability to limit or even eliminate local threats to the environment - reduction of the risk of disturbing particular compounds of the ecosystem through actions that are convergent with their primary activity, for instance in the cost reduction aspect. This is associated with, among others, limiting the energy- and resource-intensity, minimising the amount of waste and its recycling and also an increased share of renewable energy in the total energy balance in these enterprises (Koszarek-Cyra, 2016). It needs to be explained here that still a higher level of a pro-environmental attitude can be observed among large and medium-sized enterprises, however, this is justified and stimulated by legislation, e.g. restrictions in the scope of Environmental Management Systems implementation compliant with ISO 14001 or EMAS- Eco-Management and Audit Scheme or ISO 14064 (Lee et al, 2017). To sum up this part of the paper and at the same time justifying the adopted in the title subject of the research, it needs to be indicated that a stimulant to the activeness of micro and small enterprises is pro-environmental culture acceleration and thus, growth of pro-environmental awareness. In the paper its author attempts to evaluate this awareness and its maturity level based on the selected sample of micro and small enterprises.

\section{TAXONOMY OF PO-ENVIRONMENTAL AWARENESS IN THE CONTEXT OF MICRO AND SMALL ENTERPRISES}

Care for the natural environment, the nature of environmental threats to human existence has not only resulted in general progress trends in the economy considering the natural environment such as sustainable development or corporate social responsibility (CSR). This has also influenced the changes in social standards and development of pro-environmental ethics, whose most important assumption is to eliminate actions that constitute a threat to the natural environment, which can be unambiguously recognised as immoral (Poskrobko, 2007) (Poskrobko and Poskrobko, 2012). While discussing the pro-environmental ethics it should also be stressed that it comprises issues related to the man's attitude to animated and non-animated nature 
and the entire Earth's ecosystem. Its subject are values, principles, imperatives and standards that regulate or could regulate the binary man-environment relationships (Poskrobko and Poskrobko, 2012). It also needs to be stressed here that the foundation and the primary benchmark both in case of ethics and the aforementioned pro-environmental culture is pro-environmental awareness. The awareness itself means on the one hand the ability to realise something, state of consciousness characteristic for man, and also, which needs to be stressed in the present paper: common views and objectives common for a specific group (Doroszewski, 2018). Referring to the abovementioned definition, pro-environmental awareness means an ability to recognise the importance of the natural environment, which man is symbiotic with, for his proper existence,. Simultaneously, man possesses knowledge, skills, social competences, thanks to which it is possible to identify heterogeneous environmental threats and also the ones that are the outcome of his activity. Surely, it should be stressed that awareness i san equivocal notion. It can be also defined as the whole of ideas, attitudes, values and opinions about the environment as man's living place (Gadenne et al., 2010) (Koszarek-Cyra, 2016). Currently, while analysing pro-environmental awareness in the abovementioned meaning two elementary attitudes are considered (Papuziński, 2006):

- a pragmatic attitude aimed at caring for environment carried out through preventing environmental threats,

- a systemic approach being a set of projects related to social transformations aimed at creating a pro-environmental civilisation.

In a narrower grasp in turn, pro-environmental awareness can be defined as an aggregate of knowledge, views and perceptions in man's influence on the environment's condition as well as possibilities, tools and measures that can be used to protect it. In the literature on the subject pro-environmental awareness is also perceived as the awareness of threats and their impact on man's needs (Gliński, 1996). Indirectly, the ability to identify the threats can also lead to a willingness to search for information and growth of knowledge related to environmental protection. This is associated with an ability to assess the surroundings with an emotional involvement but also pro-environmental attitudes, which influence the behaviours and motivate to actions aimed at improving the condition of the natural environment. In this context, in the literature on the subject, for example according to T. Burger, four essentially different categories of proenvironmental attitudes can be distinguished: full subordination of the natural environment to man, who believes that is entitled the right to benefit from it unidirectionally; pro-environmental indifference that characterises persons disinterested in the environmental protection issues; pro-environmental passiveness of persons who are in favour of the natural environment, but do not implement proenvironmental actions and a pro-environmental attitude associated with a large interest in the environmental issues and a willingness to take active proenvironmental actions.

Referring to micro and small enterprises - the subject distinguished in the present paper's title, one must also recognise the importance of their perception of the natural environment, while carrying out their primary activity, for the correct internal existence, but first of all harmonious, pro-environmental interdependencies between them and their surroundings. Micro and small enterprises while carrying out their green activity related to reduction of energy- or resource-intensity should also 
possess the ability of continuous and permanent evaluation of the environment. This will be reflected in the growth of their pro-environmental awareness, but most importantly the awareness of social belonging, which primarily concerns local belonging that can be indirectly translated in a national or even global grasp. The pro-environmental awareness of micro and small enterprises can be evaluated in a multifaceted manner (Huang et al., 2011). However, as it has been indicated above the most important thing is the relations of this awareness in the context of heterogenous attitudes of micro and small entrepreneurs. It is also crucial to identify the impact of the growth in the pro-environmental awareness on the ability to transform indifferent or passive pro-environmental attitudes towards the offensively active ones - pro-environmental attitudes (Berrone and Gomez-Mejia, 2009).

Accepting the model of pro-environmental awareness growth developed by $\mathrm{B}$. Poskrobko as an etalon (Poskrobko B, 2007) (Poskrobko and Poskrobko 2012), the growth in the pro-environmental awareness of micro and small enterprises can be presented as chronological levels of its maturity growth. These levels have been presented in Table 1.

Table 1

Chronological maturity levels of pro-environmental awareness in micro and small enterprises

\begin{tabular}{|c|l|}
\hline \multicolumn{2}{|c|}{ LEVELS OF PRO-ENVIRONMENTAL AWARENESS GROWTH IN MICRO AND } \\
SMALL ENTERPRISES
\end{tabular}

Source: own elaboration based on (Poskrobko B, 2007) (Poskrobko and Poskrobko 2012)

External instruments that support pro-environmental awareness growth in micro and small enterprises need to be indicated here, which include: administrative and legal support mechanisms, external financial support mechanisms (preferential credits, subsidies from the EU funds, municipal subsidies, subsidies of the National or Provincial Environmental Protection Funds), educational programmes for micro and small enterprises. 
In the next section of the paper the author, according to the subject matter defined in the title, focuses on presenting the results of the research aimed at assessing the awareness of micro and small enterprises that were selected in the research process.

\section{PRO-ENVIRONMENTAL AWARENESS OF RESEARCHED ENTERPRISES}

The research "Green activity of micro and small enterprises" in the scope of proenvironmental awareness of micro and small enterprises was conducted in the group of beneficiaries included in the project "Before we are suffocated by SMOG" (the author of the paper, co-initiator, co-author and expert in the project) financed by the National Environmental Fund. Project's objective was to raise the awareness and educate local community, including SMEs, in the area of environmental protection (especially in the aspect of low emission counteracting). The project was carried out in the years 2015 - 2017 and the research sample was $\mathrm{N}=134$ - micro and small enterprises. Selection of the sample was purposeful - the subject of the research constituted enterprises that accepted invitations for trainings carried out in the form of webinars. This research was also associated with the doctoral thesis of Aleksandra Koszarek-Cyra (Koszarek-Cyra, 2016) „Environmental management in small and medium-sized enterprises of the Silesian voivodeship" supervised by the author of the paper. In the first place general issues were subject to research, which were convergent with the environmental awareness of the analysed group of enterprises, such as: the nature of their responsibility for the natural environment, role and nature of environmental protection in their organisations' strategies, evaluation of their organisations' influence on the condition of the natural environment in the immediate surroundings. Due to the requirement of a synthetic presentation, in the present paper the results of general issues convergent with pro-environmental awareness are presented in a descriptive form for the cumulated group of micro and small enterprises.

In case of the nature of responsibility for the natural environment, $63 \%$ of the respondents in the cumulated group of micro and small enterprises declared that it was definitely significant, while $32 \%$ indicated that it was one of the important areas that should have been considered in their primary activity. Only $5 \%$ of the respondents indicated that these were insignificant issues in their business activity. With reference to the role and nature of environmental protection in the strategies of the researched organisations, $33.5 \%$ of the surveyed micro and small enterprises indicated that it was very important in the context of pro-environmental functioning of their organisation, $45 \%$ determined the nature of pro-environmental activity in their organisations' strategies. Also, it should be distinguished that $10.5 \%$ of the survey respondents recognised as an important one - absorption of environmental protection into their strategies, but it concerns medium-sized and large enterprises exclusively. The remaining part of the researched micro and small enterprises $-11 \%$ believed that incorporating elements of environmental protection was insignificant, it was just a trend and it should not have concerned their enterprises. While evaluating the impact of the researched entities' business activity onto the condition of the natural environment in their immediate surroundings, it was determined that $19 \%$ of the population recognised this impact as a high, $46 \%$ attributed a high impact on the natural environment to their business activity and $19.5 \%$ indicated a medium level of their impact on the environment. It should be also stressed that compared to the previously researched general issues of pro-environmental awareness evaluation, as 
many as $23 \%$ of the survey respondents declare that the impact of their business activity onto the natural environment remains insignificant.

The results of the abovementioned research prove that contemporary micro and small enterprises are aware of the fact that their business activity produces an impact onto the natural environment. However, this awareness is not always translated into the pro-environmental activity/green activity, in convergence with their business/commercial activity.

\section{MATURITY LEVELS OF PRO-ENVIRONMENTAL AWARENESS IN RESEARCHED ENTERPRISES - DISCUSSION}

The abovementioned research in the scope of pro-environmental awareness in micro and small enterprises have been extended by the author of the present paper with self-evaluation conducted by these entities and assigning themselves to particular maturity levels of pro-environmental awareness (maturity levels have been summarised in the present paper - point 3). Each of the owners or managers in the researched entities having acquainted themselves with the determinants assigned to particular levels of pro-environmental awareness declared the level of their proenvironmental maturity. A synthetic summary of the obtained collective results, in this case due to their significance in the context of the subject matter of the paper, has been presented in Fig. 1.

\section{LEVELS OF PRO-ENVIRONMENTAL AWARENESS MATURITY GROWTH IN MICRO AND SMALL ENTERPRISES}

- LEVELS OF PRO-ENVIRONMENTAL AWARENESS MATURITY GROWTH IN MICRO AND SMALL ENTERPRISES

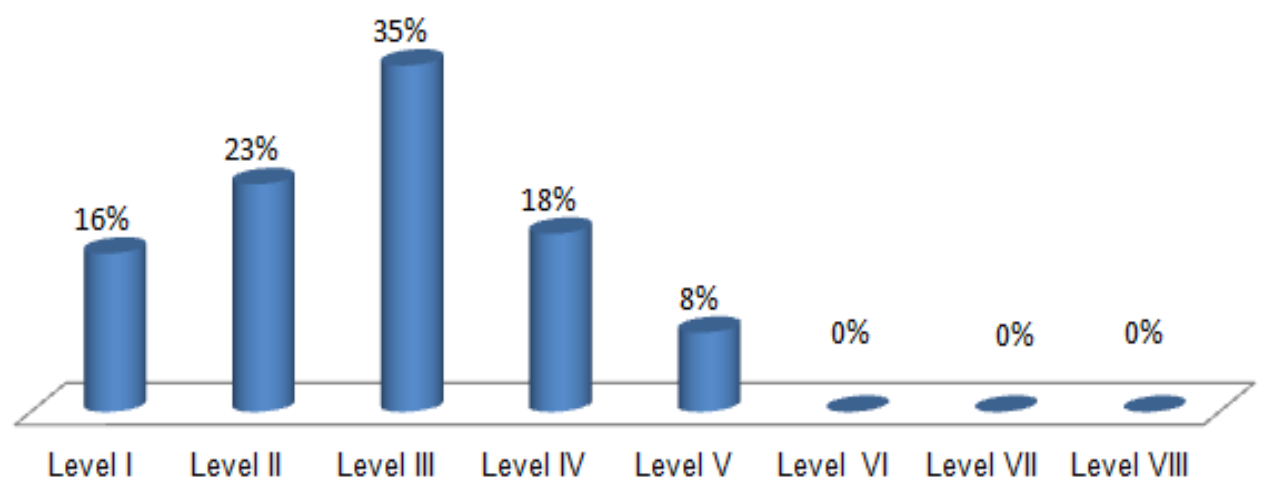

Fig. 1. Indication of pro-environmental awareness maturity levels

Based on the adjustment of the researched micro and small enterprises to maturity levels of their pro-environmental awareness it can be concluded that only $16 \%$ of the surveyed micro and small enterprises have barely reached the first level, possessing the abilities limited to identifying the symptoms and origins of environmental degradation. $23 \%$ of the entrepreneurs declared they had already reached the second level - they can perceive effects of environmental degradation. The ability to perceive the value of non-degraded environment, that is the third level of pro-environmental awareness maturity, declared $35 \%$ of the surveyed population. $18 \%$ of the survey respondents were convinced that their maturity of pro-environmental awareness is even higher - they perceive environmental threats not only in the local scale of the 
conducted activity, but also in the macro scale. However, it needs to be stressed at this point of the discussion that first four levels refer to the ability to identify threats and their environmental outcomes. The fifth level constitutes a threshold where the willingness of enterprises to react to the external social pressure begins, which is associated with undertaking and carrying out elementary/individual tasks for environmental protection. In this case only $8 \%$ of micro and small enterprises declare they belong to this level. Despite pro-environmental awareness of the enterprises, which is justified by their belonging to lower levels, none of the respondents declared offensive attitudes of pro-environmental changes, did not assigned themselves to the sixth level. Thus, nobody indicated either that they were introducing systemic changes in three basic areas: product manufacturing, production technology as well as organisation and management (level VII). None of the researched enterprises declared they possessed the ability to entirely eliminate threats that influence the risk of disturbing the compounds of the ecosystem, in the context of pro-environmental security (level VIII).

\section{CONCLUSION}

To sum up, micro and small enterprises are aware of the threats - their impact on the natural environment. They also possess the ability to identify threats, perceive value, non-degraded environment, and even as the results of the research shows - the ability to react to the external social pressure, which is associated with undertaking and carrying out elementary/individual actions for environmental protection. The abovementioned facts prove that micro and small enterprises are not indifferent in the context of environmental protection. However, it is difficult to recognise their activeness in this area as mature one. Currently, this is not reflected dynamically in a change to their pro-environmental culture or a transformation of their proenvironmental attitudes. This still confirms their pro-environmental passiveness. Micro and small enterprises perceive the nature of threats and therefore the need to protect the environment. However, they are not entirely capable of implementing heterogeneous pro-environmental actions and adopting offensive attitudes. Single pro-environmental actions that are carried out, are actually stimulated by the reduction in the cost of conducted business activity, e.g. savings of: water, resources/materials, energy and also recycling or subsiding investments in the scope of prosumer energy (micro-installations of renewable energy sector) (Kucęba et al., 2018). To conclude, the present maturity level of pro-environmental awareness in micro and small enterprises is not dynamically reflected in their greenness of the conducted business activity.

\section{REFERENCES}

Berrone P., Gomez-Mejia L.R., 2009. Environmental performance and executive compensation: an integrated agency-institutional perspective. in: Acad. Manag. J., 52 (1), 103-126. DOI: 10.5465/AMJ.2009.36461950

Bos-Brouwers H.E.J., 2010. Corporate sustainability and innovation in SMEs: Evidence of themes and activities in practice. Business Strategy and the Environment, Volume19, Issue7, November, 417-435. DOI: 10.1515/emj-20160024.

Burger T., 2005. Green awareness of Polish society. Warsaw, 2005, 9-11 (Institute of 
Economy and Urban Area).

Doroszewski W., 2018. Polish language dictionary, PWN, https://sjp.pwn.pl/szukaj/\%C5\%9Bwiadomo\%C5\%9B\%C4\%87.html [accessed: 28.12.2018]

Gadenne D. L., Kennedy J., McKeive C., 2009. An Empirical Study of Environmental Awareness and Practices in SMEs. Journal of Business Ethics (Springer), Volume 84, Issue 1, January, 45-63. DOI: 10.1177/1086026618803720

Gliński P., 1996. Polish green activists. Social movement at the time of transformation. Warsaw, 1996, 133-145.

Hoogendoorn B., Guerra D., van der Zwan P., 2015. What drives environmental practices of SMEs? Small Business Economics An Entrepreneurship Journal (Springer), Volume 44, Issue 4, April, 759-781, DOI: 10.1007/s11187-014-96189.

Huang I.B., Keisler J., Linkov I., 2011. Multi-criteria decision analysis in environmental sciences: Ten years of applications and trends. Science of The Total Environment (Elsevier), Volume 409, Issue 19, September 2011, 3578-3594. DOI: 10.1016/j.ecolind.2012.10.005

Koszarek-Cyra A., 2016. Pro-environmental actions of micro-enterprises in the European Union. In: Kulej-Dudek E., Kobis P.(eds.), Development and improvement of organisation's functioning. Enterprises in the era of new technologies, innovative and socially responsible actions, Czestochowa, 2016, 122-131 (Publishing House of Czestochowa University of Technology).

Kucęba R., Zawada M., Szajt M., Kowalik J., 2018. Prosumer Energy as a Stimulator of Micro- Smart Grids Development - on the Consumer Side. 2nd International Conference on Energy and Environmental Science (ICEES 2018), Kuala Lumpur, Malezja. Web of Science Core Collection, Scopus.

Lee S.M., Noh Y., Choi D, Sung Rha J., 2017. Environmental Policy Performances for Sustainable Development: From the Perspective of ISO 14001 Certification. Corporate Social Responsibility and Environmental Management, 24:2, 108-120. DOI: $10.1002 /$ csr.1395

Liu D., Chang Q., 2015. Ecological security research progress in China. Acta Ecologica Sinica Volume 35, Issue 5, October, Pages 111-121 (Esevier).

Social Research Office INDEKS 2014. Research of the awareness of the man's personal influence on the environment. Report on social research that was carried out by the Social Research Office INDEKS on commission of the Our Earth Fund in the period May-June 2014. Accessed: https://www.mos.gov.pl/g2/ big/2014_11/81edfc1f241d2e3c20fb9596d245f9bb.pdf [22.12.2018]

Papuziński A. 2006. Pro-environmental awareness in the light of theory and practice (An outline of the political model of pro-environmental awareness). in: Problems of eco-development vol. 1, No 1 (2006), 33-40.

Poskrobko B., 2007. Managing the environment, Warsaw, (PWE).

Poskrobko B., Poskrobko T., 2012. Managing the environment in Poland. Warsaw, (PWE).

Tidd J., 2001. Innovation management in context: environment, organization and performance. International Journal of Management Rewievs, (c) John Wiley \& Sons Ltd and the British Academy of Management, Volume3, Issue3, September 2001, 169-183, DOI: 10.1111/1468-2370.00062. 